Conclusions This network meta-analysis is the first to compare and rank firstline maintenance therapies in aOC. It indicates that PARPI have better outcomes than AA. It also demonstrates that individual PARPI vary in frequency of $\mathrm{AE} \geq 3$ as well as clinical efficacy across mutation subtypes.

\title{
IGCS20_1354
}

\section{PATTERNS OF CARE AND OUTCOMES OF VULVAR CANCER TREATMENT IN WOMEN WITH OR WITHOUT HIV INFECTION IN BOTSWANA}

${ }^{1} S$ Sakamuri ${ }^{*},{ }^{1} \mathrm{E}$ MacDuffie, ${ }^{2} \mathrm{R}$ Luckett, ${ }^{3} \mathrm{~T}$ Moloi, ${ }^{3} \mathrm{~T}$ Ralefala, ${ }^{3} \mathrm{M}$ Bvochora-Nsingo, ${ }^{3} \mathrm{~N}$ Zetola, ${ }^{1} \mathrm{~S}$ Grover. ${ }^{1}$ University of Pennyslvania, USA; ${ }^{2}$ Beth Israel Deaconess Medical Center, USA; ${ }^{3}$ University of Botswana, Botswana

\subsection{6/ijgc-2020-IGCS.284}

Objective Vulvar cancer rates are increasing in low-and middle-income countries with high incidence of HPV and HIV co-

a. Kaplan Meier Curve by FIGO stage

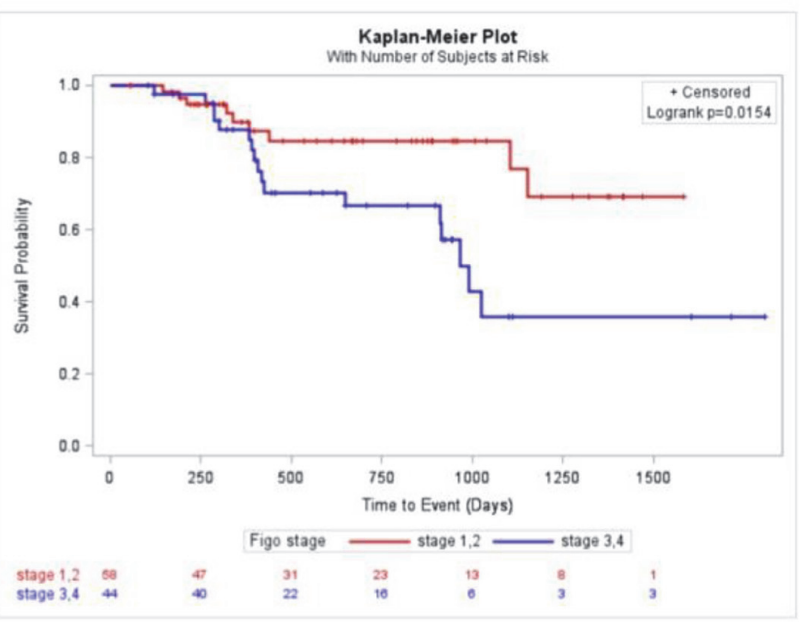

infection. Patterns of care in low-resource settings are not yet well described.

Methods Women with vulvar cancer who presented to an oncology clinic in Botswana from January 2015 through October 2019 were prospectively enrolled in this observational cohort study. Factors associated with survival including age, HIV status, stage, and treatment were evaluated.

Results 128 women with vulvar cancer were enrolled with a median age of 42 years. $46.6 \%$ presented at late stage (stage III/IV). 89\% $(\mathrm{n}=107)$ of patients were living with a well-controlled HIV infection with a median CD4 count of 461 cell/ul (IQR 300.5-684.5) and high level of viral suppression $(95 \%$ with viral copies < 400). Surgery was performed in $25(20.8 \%)$ patients. 29 (24\%) patients received chemotherapy. $81 \quad(67.5 \%)$ received radiation therapy. Adjusted analysis controlling for HIV, age, stage, surgery, chemotherapy demonstrated no differences in survival at 32 months by HIV status (HR, 0.426; 95\% CI, 0.112 1.5976). Older age (HR, 1.06; (95\% CI, 1.02-1.11) was associated with worse survival while receipt of surgery was associated with improved survival (HR 0.09, 95\% CI $0.01-0.74)$.

Abstract 332 Figure 1 Kaplan Meier curve of multivariate survival analysis of patients with vulvar cancer by FIGO stage (1a), HIV status (1b), and Receipt of surgery (1c) 
Conclusions Women in Botswana with vulvar cancer have a high rate of HIV infection and present at a young age. While decreased survival was associated with older age, HIV status did not impact survival. One-fifth of patients received surgery, which was associated with improved survival. Future efforts to identify patients early with limited disease burden and increase surgical capacity may improve outcomes.

\section{IGCS20_1356}

\section{STANDARDIZATION OF CAREGIVER AND NURSING PERIOPERATIVE CARE ON GYNECOLOGIC ONCOLOGY WARDS IN A RESOURCE-LIMITED SETTING}

1J Wong*, ${ }^{2} \mathrm{P}$ Mulamira, ${ }^{3} \mathrm{~S}$ Arizu, ${ }^{2} \mathrm{M}$ Nabwire, ${ }^{2} \mathrm{D}$ Driwaru, ${ }^{2} \mathrm{D}$ Mugabi, ${ }^{2} S$ Nabulime, ${ }^{2} E$ Nankya, ${ }^{2} \mathrm{R}$ Batumba, ${ }^{2} \mathrm{~A}$ Okoth, ${ }^{2} \mathrm{JL}$ Namugga, ${ }^{2} \mathrm{~J}$ Ajeani, ${ }^{2} \mathrm{C}$ Nakisige, ${ }^{4} \mathrm{SM}$ Ueda, ${ }^{3}$ LH Havrilesky, ${ }^{3} \mathrm{PS}$ Lee. ${ }^{1}$ Duke University School of Medicine, USA; ${ }^{2}$ Uganda Cancer Institute, Uganda; ${ }^{3}$ Duke Cancer Center, USA; ${ }^{4}$ University of California San Francisco, USA

\subsection{6/ijgc-2020-IGCS.285}

Introduction In Kampala, Uganda, there is a cultural practice for patients to have a caregiver present for the duration of a hospitalization. At the same time, nursing support is limited. This quality improvement project aimed to standardize caregiver and nursing perioperative care at the Uganda Cancer Institute and Mulago Women's Hospital gynecologic oncology wards.

Methods We developed and evaluated a multidisciplinary intervention involving standardization of nursing care, patient education, and family member integration from October 2019 July 2020. Data were abstracted from medical records and patient interviews pertaining to the following outcomes: 1) pain control; 2) infections during hospitalization; 3) nursing documentation of medication administration, pain quality, and patient checks, and 4) patient and caregiver education. Descriptive statistics, Fisher's exact test, and independent sample t-test were applied.

Results Data were collected from 25 patients undergoing major gynecologic procedures (table 1). Pre- $(\mathrm{N}=14)$ and

Abstract 333 Table 1 Comparison of pre- and post-intervention outcome measures

\begin{tabular}{|l|l|l|l|}
\hline & $\begin{array}{l}\text { Pre- } \\
\text { intervention, } \\
\mathrm{n}(\%)\end{array}$ & $\begin{array}{l}\text { Post- } \\
\text { intervention, } \\
\mathrm{n}(\%)\end{array}$ & \\
\hline Pre-operative measures & $\mathbf{N}=\mathbf{9}$ & $\mathbf{N}=\mathbf{1 0}$ & \\
\hline Patient or family purchased pain medications before surgery & $0(0 \%)$ & $\mathbf{1}(10 \%)$ & $\mathrm{p}=0.582$ \\
\hline Received antibiotics before surgery & $1(11.1 \%)$ & $0(0 \%)$ & -- \\
\hline Received wound care education & $0(0 \%)$ & $8(80 \%)$ & $\mathrm{p}=\mathbf{0 . 0 0 1}$ \\
\hline Received education on what to expect after surgery & $0(0 \%)$ & $6(60 \%)$ & $\mathbf{p = 0 . 0 1 1}$ \\
\hline & & & \\
\hline Post-operative measures & $\mathbf{N = 9}$ & $\mathbf{N}=\mathbf{1 0}$ & \\
\hline $\begin{array}{l}\text { Family member/caregiver documenting on the attendant } \\
\text { flowsheet on POD1 }\end{array}$ & $0(0 \%)$ & $0(0 \%)$ & -- \\
\hline Presence of post-op infection by day of discharge & $0(0 \%)$ & $0(0 \%)$ & -- \\
\hline Documentation in the chart & & & \\
\hline $\begin{array}{l}\text { Number of documented nursing checks by POD1, median } \\
\text { (range) }\end{array}$ & $\mathbf{N = 1 4}$ & $\mathbf{N}=\mathbf{1 1}$ & \\
\hline Documentation of pain quality by POD1 & $5(1-8)$ & $\mathrm{p}=0.266$ \\
\hline Documentation of pain score at least once by POD1 & $5(35.7 \%)$ & $4(36.4 \%)$ & $\mathrm{p}=0.689$ \\
\hline $\begin{array}{l}\text { Documentation of pain medication administration on POD0 } \\
\text { and POD1 }\end{array}$ & $13(92.9 \%)$ & $0(0 \%)$ & -- \\
\hline Documentation of intraoperative antibiotic administration & $9(64.3 \%)$ & $10(90.9 \%)$ & $\mathrm{p}=1.00$ \\
\hline Documentation on new post-op order sheet & $0(0 \%)$ & $\mathbf{p}=0.180$ \\
\hline
\end{tabular}

post- $(\mathrm{N}=11)$ intervention comparison demonstrated significant increases in preoperative patient education $(0 \%$ to $80 \%, \mathrm{p}=$ 0.001 ) and utilization of a comprehensive postoperative order form $(0 \%$ to $45.5 \%, p=0.009)$. Increased frequency in nursing documentation of patient checks and intraoperative antibiotic administration in patient charts were noted but did not reach significance. There was no change in infection rate, pain score utilization, caregiver documentation, or preoperative medication acquisition.

Conclusion Our findings suggest that patient- and family-centered perioperative care can be improved through standardization of nursing care, improved education, and integration of caregivers in a nursing-limited setting.

\section{IGCS20_1357}

\section{DETERMINANTS OF GYNECOLOGIC - ONCOLOGY REFERRAL AND MANAGEMENT OF OVARIAN MASSES IN THE PHILIPPINE GENERAL HOSPITAL (PRELIMINARY RESULTS OF THE OVERA STUDY)}

${ }^{1} \mathrm{C}$ Velayo, ${ }^{2} \mathrm{~K}$ Reforma, ${ }^{2} \mathrm{R}$ Sicam*, ${ }^{2} \mathrm{M}$ Hernandez-Diwa, ${ }^{2} \mathrm{~A}$ Sy. ${ }^{1}$ University of the Philippines, Philippines; ${ }^{2}$ Philippine General Hospital, Philippines

\subsection{6/ijgc-2020-IGCS.286}

Introduction Timely referral to a gynecologic-oncologist (GO) in the management of an ovarian mass could make a significant difference in the prognosis and survival of patients. Understanding the factors affecting referral decisions in a teaching institution will improve strategies for supervision of trainees as well as overall patient outcomes.

Methods This is an ongoing randomized controlled trial using OVERA among Filipino women with ovarian masses in a university hospital. OVERA results were made available pre-operatively to high risk (M) and low risk - disclosure (BD) groups, but not to the low risk - Non-Disclosure (BND) group. The impact of clinical and biochemical factors on the decision for GO referral was evaluated through a questionnaire.

Results There were 347 women included in this analysis. Only 30.84\% (n: 107, CI: 26.01-35.99\%) were referred to a GO prior to surgery. More than half of the women assigned in the $\mathrm{M}$ group $(79,54.48+)$ were referred in contrast to $\mathrm{BD}(17,17+)$ and $\mathrm{BND}(11,10.78+)$ groups $(\chi 2$ : $66.22, \mathrm{p}<0.01)$. Only three women $(0.87+$, CI: $0.18-$ $2.53 \%)$ had post-operative complications, less than a tenth (n: 13/335, CI: 2.08-6.54\%) had a gynecologic-oncologist as the primary surgeon, and more than a quarter (n: 77) 252, CI: $24.93-36.65 \%$ ) of patients needed intra-operative referral to a specialist. Among all the factors investigated, only HE-4 levels (z: 2.45, p: 0.01) influenced non-referral to an oncologist.

Conclusion Subspecialty referral is underutilized even in the presence of key determinants of increased malignancy risk. Recognition of available assessment factors will help optimize patient care. 